ITPD

5,2

Received 5 August 2021

Revised 19 October 2021

Accepted 20 October 2021

\section{Antecedents and consequence of the consumer's psychic distance in cross-border e-commerce}

\author{
$\mathrm{Xi}$ Chen \\ International Trade and Business, Kyung Hee University, \\ Seoul, Republic of Korea, and \\ Hag-Min Kim \\ Department of International Business and Trade, Kyung Hee University, \\ Seoul, Republic of Korea
}

\begin{abstract}
Purpose - The psychic distance often hinders the interaction between cross-border e-commerce (CBEC) and consumers. This paper aims to discuss the issues of psychic distance of consumers in the CBEC. In addition, it attempts to explain the factors that affect psychic distance from three dimensions of culture, economy and politics and the two different shopping behaviors caused by psychic distance.

Design/methodology/approach - This research incorporates both theoretical and empirical studies. In this study, 249 validated questionnaires were selected from 300 Chinese CBEC consumers by snowball sampling, and the relationship between variables was tested using structural equation model (SEM). This was done through online research, and it is ensured that the data obtained are first-hand information.

Findings - The paper suggests the theoretical model operationalizing CBEC psychic distance and the empirical analysis results show that all the six influencing factors have a positive impact on the psychic distance of consumers. Logistics infrastructure barriers in the economic dimension are confirmed as the major influencing factor, and the significance of the political dimension is relatively small. Based on consumers' uncertainty of various kinds of information, psychic distance subconsciously causes consumers to deviate in the cross-shopping process.

Originality/value - Currently, research on e-commerce mainly focuses on saving trade costs and improving consumer welfare, while research on the internal impact of CBEC on consumers is insufficient. Psychic distance is a new concept in the field of cultural and social research. The originality of this paper is that the concept of psychic distance has been extended from overseas invested enterprises to research with CBEC consumers as the selected object. The obstacles of CBEC have been widely studied, but few are related to the closeness of consumers, or the inner feelings of consumers are ignored. In the context of CBEC, this paper lists the actual external factors and potential threats that may affect consumers' consumption concerns of CBEC from three dimensions. The real emotions of consumers in the face of these difficulties indirectly affect the purchase satisfaction and reduce the purchase desire. Consumer psychic distance is a real phenomenon in cross-border shopping, and it is almost inevitable for these difficulties. On the premise of inevitability, high psychic distance will slow down cross-border shopping in the eyes of consumers.
\end{abstract}

Keywords Cross-border e-commerce, Psychic distance, Social, Economical, Political barriers, Satisfaction, Purchasing delay

Paper type Research paper

(C) Xi Chen and Hag-Min Kim. Published in International Trade, Politics and Development. Published by Emerald Publishing Limited. This article is published under the Creative Commons Attribution (CC BY 4.0) licence. Anyone may reproduce, distribute, translate and create derivative works of this article (for both commercial and non-commercial purposes), subject to full attribution to the original publication and authors. The full terms of this licence may be seen at http://creativecommons.org/licences/by/4.0/ legalcode

This work was supported by the Ministry of Education of the Republic of Korea and the National Research Foundation of Korea (KNRF-2019042083). 


\section{Introduction}

In the 21st century, economic globalization and Internet technology have brought great challenges and opportunities for the development of international trade and business. There is no doubt that electronic commerce has a significant impact not only on society, finance, politics and culture but also on people's daily lives and purchasing habits. The cross-border ecommerce (CBEC) has promoted the development of international trade, which increases the volume of cross-border trade and contributes to a country's economy (Chen et al., 2020) and world economy as well. Xue et al. (2016) defines "CBEC" that is done through the Internet, e-mail and other forms of transaction in different countries and regions different from direct face-to-face transactions. Hence, it is also known as a novel pattern of cross-border trade that takes electronic interaction as its means and makes distances short between markets and products in space and time.

The term of psychic distance refers to the difference of objects between nations. Therefore, the $\mathrm{CBEC}$ psychic distance can be interpreted as the perceived difference between international consumers (online buyers) and cross-border suppliers or CBEC platform providers. The perception of the overall similarities and differences between foreign and domestic online retailers is the result of consumers' specific values and perceptions towards foreign online retailers. Safari et al. (2013) study claims that customers that perceive an elevated level of psychic distance towards a foreign country often associate it with more difficulties compared to the domestic country. There are four antecedents that determine how large or small the psychic distance between the two countries is for the individual (Sousa and Bradley, 2006). They include cultural factors (e.g. norms, language), values, customs and the economic and legal situation of the country. "The death of distance" is indeed an accurate description of the impact of the Internet. It is worth noting that in terms of e-commerce, it is only limited to domestic. The overseas mode of CBEC has been introduced for a long time, but as Chinese consumers, there are hidden dangers and concerns in overseas direct purchase. The psychic distance of CBEC consumers can effectively explain the root cause of this phenomenon. Given the growing importance of e-commerce, especially in cross-border retail, understanding how consumers perceive foreign international online suppliers (IOVs) is essential to business success. This new concept of psychic distance in CBEC environment not only aims at new entrants but also at consumers who have already carried out shopping experience in CBEC. Especially for new entrants, they may experience greater perceptual difficulties than expected, or it is difficult to deal with things they are not familiar with for the first time. For consumers who have had their first cross-border shopping experience, they are likely to turn to other shopping platforms after experiencing psychologically bad shopping experience.

The paper is organized as follows: Section 2 introduces the conceptual model and literature to ensure the originality of the development of CBEC based on psychic distance. Section 3 introduces the hypothesis and the model for CEBC psychic distance. Section 4 provides empirical results for the model and explains how the data were acquired. Finally, Section 5 sums up the results of this paper and shows the conclusion and cultural economic and political implications of the findings.

\section{Conceptual model and literature review}

\subsection{Conceptual model}

Mexico and Russia, one of the world's largest CBEC markets, rounded out the top five. India takes third position with 50 million e-buyers. The growing number of Internet users means that these countries still have space for cross-border consumption expansion. Statistically, Chinese consumers are still in the lead (Figure 1). Therefore, this paper conducts further research and observation on Chinese cross-border consumers. By analyzing the market share

Cross-border e-commerce and consumers 
ITPD

5,2

\section{8}

Figure 1.

E-buyers of crossboarder e-commerce and the largest markets in the world (millions) of cross-border business in e-commerce, cross-border shopping accounted for 14 and $15 \%$ of total online shopping in North America and Western Europe. The underlying reason for this result is that both markets are almost saturated, and the items needed can be procured at favorable prices in the country of residence. Across Asia, there are obvious differences between countries. Hong Kong, Singapore and Vietnam accounted for 31, 43 and 55\% of CBEC purchases. In Indonesia, India and Japan, the proportion is just $12 \%$. China, with $20 \%$ of online cross-border purchases from outside Asia, is in the middle of the ranking.

The conceptual model (Figure 2) of this study is based on the barriers of CBEC, development extended to psychic distance at the consumer level and finally spread from the psychic distance to the possible purchase actions and satisfaction of consumers. The adaptation level theory explains that the basis of an individual's judgment on a stimulus depends on their past experiences and/or recollections of the encounters they have had with similar stimuli in the past. It is very important to find out the reasons why consumers are hesitant to reduce barriers in related fields and reduce their psychological level through adaptation theory. In addition, psychic distance can be used as a proxy to measure CBEC consumer satisfaction. Psychic distance can be a good yardstick to distinguish dissatisfied groups from satisfied groups and, more strictly, their hesitation.

Consumer purchasing delay is reflected in the following three aspects: (1) overall hesitation, (2) giving up after placing an item in the shopping cart and (3) hesitation at the final click. Overall, hesitation tends to be perceived as risk or uncertainty in the medium; the abandonment of shopping cart usually refers to the abandonment of shopping cart caused by the expensive extra cost (transportation cost, etc.) through more price comparison; hesitation at the final click is more concerned about payment security and return and exchange policy after purchase. Perceived uncertainty, media/channel innovation, situational factors and consumer characteristics were used to predict online shopping hesitation (Cho et al., 2006).

Yu and Dean (2001) describe consumer dissatisfaction as a generalized psychological state generated by the combination of emotions surrounding uncertain expectations and consumers' previous feelings of customer experience. The uncertainty of psychic distance shows that consumers lack control over the future after shopping. The level of satisfaction or dissatisfaction is reflected from perceptions and attitudes from their previous experiences.
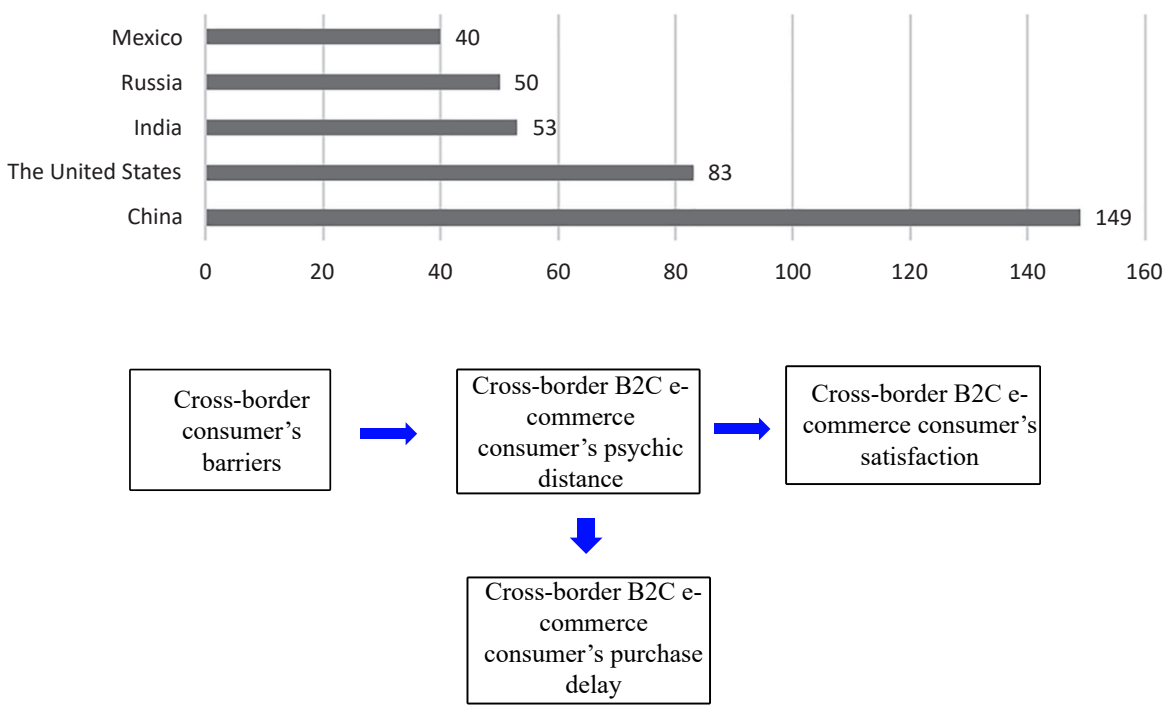

commerce
consumer's purchase
delay

Cross-border B2C ecommerce consumer's satisfaction
Figure 2.

Conceptual model of CBEC psychic distance 
When CBEC consumers try shopping for the first time, their expectations are often reduced due to communication difficulties and ambiguous information. After the purchase is completed, the next state would be undesirable such that it may not be repurchased because the delivery time is inconsistent with their expectations. The phenomenon of this sense of gap is actually psychic distance, which is also the worry of hidden dangers. It is inevitable that there will be psychological doubts when contacting new things (CBEC) for the first time.

\subsection{Logical framework of psychic distance in $C B E C$}

Early psychic distance is in many ways synonymous with cultural differences, but culture as international trade, politics and development understood from Hofstede's dimension is not an accurate measure of psychic distance (Sousa and Bradley, 2006). Therefore, psychic distance seems to be a more subtle and complex concept than simply examining cultural differences. There are good reasons to believe that psychic distances are not symmetrical in comparison with the geographical and cultural distances traditionally measured. That is, the perceived distances from A to B and B to A are not necessarily equal (Shenkar, 2001). Therefore, it is important to recognize the consumers' sample in the study because A country's consumer psychic distance is different from the B country's consumer psychic distance. The psychic distance not only includes the concept of cultural distance but also involves business elements (Håkanson and Ambos, 2010). Psychic distance is defined as a prerequisite for trust and commitment and has different effects at various stages of a relationship between buyers and sellers. The perception of a specific country's knowledge, familiarity and understanding is also a reflection of psychic distance (Dow and Karunaratna, 2006). Similarly, Evans and Maverondo (2002) agreed that it was necessary to adopt a discriminative way to judge the difference between countries. They argue that not only the cultural adaptation and modernization factors mentioned above but also the national laws and regulations should be involved in the scope of psychic distance.

Yamin and Sinkovics (2006) propose that while the Internet can indeed reduce psychic distance, it is also a dangerous statement because it can lead one to fall into a virtual trap. Online internationalization takes place in a relatively short period of time and usually focuses on multiple market entries in a short period of time. International enterprises often ignore the degree of knowledge acquisition in the individual markets they are targeting. Therefore, the risk of becoming unfamiliar with the specific factors of the country increases, which is invisible at first sight and will affect the psychic distance. CBEC consumers are similar to multinational enterprises. It is relatively easy for them to enter the CBEC platform for shopping initially, but psychic distance often occurs in the process of overseas shopping problems. Table 1 introduces the evolution and development of psychic distance from offline to consumer psychic distance in CBEC. Table 2 introduces the antecedent factors of psychic distance of CBEC consumers.

\section{Theoretical framework and hypotheses}

Psychic distance is a subjective type of distance ("perceived differences"). A more accurate way is to ask decision-makers what they think of different host countries or using their antecedents to estimate it. In the international business and marketing research, the factors of psychic distance are related to diversity and differences on a country basis and can be divided into four distinct regions: (1) Linguistic differences and translation difficulty, (2) Cultural factors - societal norms, level of individualism or collectivism, values and customs, (3) Economic situation - existing trading links, infrastructure, local conditions, competition and investor confidence, and (4) Political and legal system - government stability and risk of instability, import tariffs, legal protection and taxation levels. The above four aspects correspond to the social and cultural, economical, political and legal difficulties faced by

Cross-border e-commerce and consumers 
ITPD 5,2
Offline psychic distance

Psychic distance is defined as the factor that prevents or interferes with the flow of information between potential and actual suppliers and customers and is considered an obstacle to international trade (Johanson and Wiedersheim, 1975). The psychic distance has also on occasion been measured through formative indicators, such as social ties, geographic ties and close political relations. When cultural distances are high, there is ambiguity between international partners about the knowledge they wish to exchange (Prime et al., 2009). Geographical distance does not merely mean a straight line between borders or capitals, as major commercial trade is also used as a measure of geographical distance (Håkanson and Dow, 2012). Managing business relationships with partners from different countries may require interaction with the government of that country. If political systems vary widely, the cost and uncertainty of interacting with distant governments can make buy-side companies more inclined to protect themselves from the uncertainty (Dow and

Table 1.

The development of CBEC based on psychic distance

\section{CBEC consumer psychic distance}

CBEC consumer psychic distance can be defined as the perceived uncertainty and additional transaction costs of cross-border consumers. When cross-border consumers feel these uncertainties, they are more concerned about avoidance. Digital distance is a special case of distant communications done via digital instruments, such as the Internet. The psychic distance of CBEC consumers in the digital environment and the perception difficulties will become personalized and subjective. Language choices are less likely to lead to misunderstandings in information or difficulties in communication. Because consumers communicate on the Internet rather than face to face, they will feel that problems in shopping have not been substantively solved. On the other hand, additional transaction costs are reflected in transportation costs and payment security considerations, due to the increased implicit concerns of new entrants unfamiliar with the process of CBEC, even if these risks do not occur. Similarly, consumers' rights and interests often change with government tax and regulatory policies, and the price changes caused by additional tax rates also make consumers have to consider the necessity of purchase

CBEC consumers. In the context of international online retail, what consumers will do when psychic distance is given is also the focus we need to pay attention to. We hypothesize that after consumers experience psychic distance, the perceptual uncertainty will produce two results: purchase delay and reduced satisfaction. For a better understanding of the psychic distance hazards on CBEC performance, a conceptual model was developed, depicted in Figure 3 below.

\subsection{Social and cultural difficulty}

Language distance is another psychic distance dimension that has received empirical confirmation in the research community (Dow and Karunaratna, 2006). Because the language of foreign online retailers may be different from that of consumers in their own countries, consumers may lose their direction in different cultural environments (Boeuf and Senecal, 2014). If they think it takes too much time to understand the content on foreign websites, they may become less willing to participate. Another study conducted by Schaffer (2000) reported that $30 \%$ of CBEC consumers just wander around the site but leave the site without buying anything because they cannot find the right information through the site. In developing countries, a large amount of uneducated and less educated people have poor access to information on the Internet (Lawrence and Tar, 2010). Even though cross-border platforms have introduced various means of artificial intelligence (AI) language translation, the limited savvy of CBEC consumers can still cause misunderstanding, confusion and difficulty in comprehension during their shopping process. As for the problem of language communication, retailers do not reach the psychological expectation of consumers.

The experiential finding suggested that with the increase of electronic interaction, people also need to communicate with suppliers in culture and spirit. Later, Lim et al. (2004) 
Factors of psychic distance in $\mathrm{CBEC}$

Definition and interpretation of each element

Language difficulty

Cultural adaptation

Logistic infrastructure

Payment infrastructure

Import tariffs

Government supervision perceived value for $\mathrm{CBEC}$ consumers goods and services
Communication across language barriers is potentially difficult for the transmission of meaning and subtext (Peltokorpi and Vaara, 2014). Using unfamiliar language to communicate is also a cost, which may reduce the

In the cross-border background, the emergence of relationship services means a differentiated adaptation (Sinkovics et al., 2007). For cultural sensitivity, online platforms can provide special relationship services for the target market. Empirical findings are further offered by Luna et al. (2002) whose research illustrated that when consumers log into websites with a similar local culture, they are likely to make less efforts in cultural cognition

In the context of CBEC, geographical distances and time differences between countries are major hindrances in achieving fast and accurate delivery. While delivery services have brought benefits to $\mathrm{CBEC}$, many consumers still regard the cost of cross-border express delivery as an addition a transaction cost, even though retailers have already built these costs into the price of their products The leaking of personal information will put consumers in a disadvantageous position, thus creating a sense of distance in the process of trading (Ganesh et al., 2010). Considering the three obstacles of payment security, inconvenient payment methods and fear of personal information disclosure, consumers can be ambivalent when it comes to cross-border shopping

As claimed by Kowalski (2005), imposing import tariffs will cause price fluctuation of goods and services and also reflect in the quantity of imported

As consumers face various barriers to participating in e-commerce, the lack of legislation may hinder the development of e-commerce, as well as lack of trust, privacy and financial security (Gibbs et al.,2003). When the quality of goods on the platform cannot be monitored, quality problems can only be dealt with afterward

\section{Cross-border e-commerce and consumers}

Table 2.

Factors of psychic distance related barriers of CBEC consumers

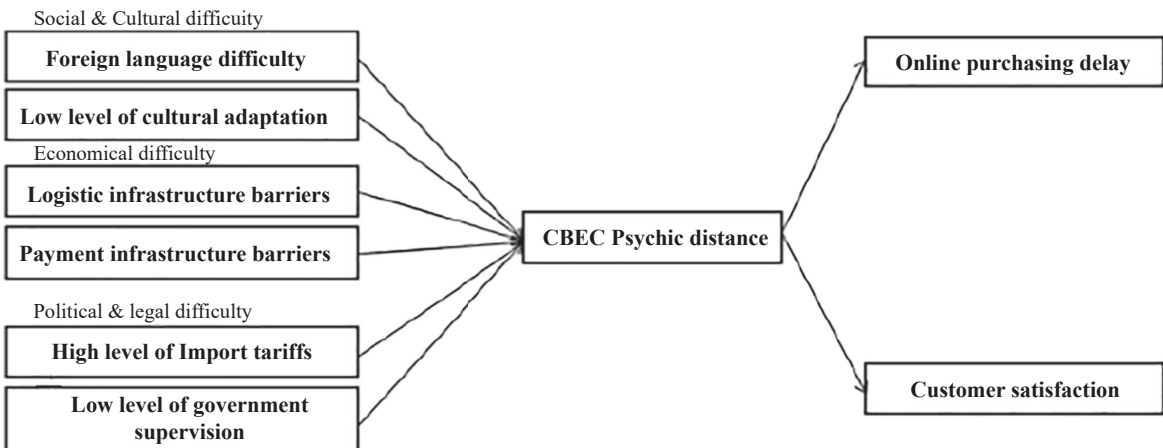

Figure 3.

Research model

confirmed these findings of cultural boundary differences in the virtual network environment. The specific cultural characteristics of consumers in countries are different. Cultural attributes create distance by influencing consumers' preferences for specific functions and making choices between alternatives. Although the world is more and more inclined to cultural integration, it is undeniable that cultural prejudice still exists to some extent. Geographical and racial differences are reflected in the way of dealing with problems. 
ITPD

5,2

162

Sometimes, products touch deeper nerves, triggering associations related to the identity of consumers as community members (Kuo and Fang, 2008). Cultural differences can be directly manifested in the content display of product information and advertising on CBEC platforms. Based on the discussions above, we develop the following hypotheses:

H1. The high level of a customer's foreign language difficulty increases CBEC psychic distance.

H2. The low level of a customer's cultural adaptation increases CBEC psychic distance.

\subsection{Economical difficulty}

Kawa (2014) proposed that through efficient logistics (availability of goods, different delivery modesand lower transport costs), not only can new consumers be attracted but also customers who have placed orders can be retained. At present, foreign retailers will produce high transportation costs when they sell their products online depending on different countries, which are generally five times more expensive than the actual domestic shipping costs (European Commission, 2016a, b). According to Ding et al. (2017), compared with domestic online shopping, the logistics delivery process is time-consuming, and there is no way to track and inquire the package's delivery process. CBEC logistics involves commodity inspection through export customs declaration and import customs clearance, which is complicated and expensive. In addition, the rate of damage and loss of parcels is much higher than that of domestic e-commerce logistics. Uncertain time and complicated logistics process make cross-border consumers have a psychological burden when they purchase goods on the platform. On the one hand, this sense of uncertainty comes from the long geographical distance, and on the other hand, it is because CBEC is a brand-new thing for the new consumers that they are more likely to undergo a psychological burden. For experienced CBEC consumers, logistics cost and time may not pose additional risk. However, for consumers who try $\mathrm{CBEC}$ for the first time, they will have doubts about the extra cost and time accuracy of logistics.

According to research, $30 \%$ of consumers leave online stores priced in foreign currencies only, and nearly $40 \%$ of consumers say they are unwilling to return to the website for shopping. Whether this feeling is real or perceived, most users in developing countries are unwilling to entrust sensitive personal information, such as sensitive credit card numbers to enterprises operating on the Internet (Lawrence and Tar, 2010). Infrastructure supporting e-payment is crucial to promoting e-commerce, which exposes the key links between e-commerce and the economic and financial base (Lawrence and Tar, 2010). Similar to logistics facilities, it is also an obstacle for consumers who first engage in CBEC shopping. In an unfamiliar platform, it is common for browsers/consumers to worry about payment insecurity and additional costs caused by exchange rate. Few consumers carefully investigate the information about payment security and privacy and mainly judge the reliability of online payments by seeking other consumers' evaluations or reviews. Thus, we develop the following hypotheses:

H3. The barriers of logistics infrastructure increase the consumer's psychic distance in CBEC environment.

H4. The barriers of payment infrastructure increase the consumer's psychic distance in CBEC environment.

\subsection{Political and legal difficulty}

Countries impose different kinds of tariffs to restrict the export and entry of other countries' goods, threatening the development of their own industries. For cross-border goods that are 
in high demand, the reduction of import tariffs should be conducive to improve the quantity of imports, to meet consumers' diversified and personalized needs and to play a positive role in ensuring the domestic industries. Differences in the level of import tariffs influence the duties charged on imported goods. There is no doubt that consumers tend to buy high-quality goods at a relatively cheap price. The cross-border consumers' worry about tariffs is that the payment price when they buy on the platform is inconsistent with the arrival price of goods. In other words, they are uncertain about whether the goods they plan to buy demands extra customs clearance fees. The CBEC platform will not deliberately emphasize the extra cost of products in customs clearance, which requires $\mathrm{CBEC}$ consumers to explore and bring difficulties to them.

Moreover, to achieve this goal in the digital context, the government should overcome practical problems on how to offer efficient risk management for national security without compromising free trade; ensure effective collection of taxes; protect the privacy of users and enterprises, while facilitating the access and exchange of information; maintain appropriate control and implementation with a high degree of cooperation between national and international institutions, enterprises, organizations and other stakeholders. Okholm et al. (2013) argued that government policies will play a positive role in the performance of CBEC, minimizing the gap between information, services and performance in the Business-toConsumer (B2C) environment. As consumers face various barriers to participating in e-commerce, the lack of legislation may hinder the development of e-commerce, as well as lack of trust, privacy and financial security (Gibbs et al., 2003). Under the government control of imperfect legislation, it is difficult to guarantee the after-sales service of CBEC, like product quality problems. It is natural for consumers to think subconsciously that the government decision-making is beyond their control. Fake products and advertising information on CBEC platforms without government supervision can also lead consumers to question the authenticity of products. Based on the above reasoning, we propose the following hypotheses:

H5. The high level of import tariffs increases CBEC psychic distance.

H6. The low-level quality of government supervision increases CBEC psychic distance.

\subsection{Online purchasing delay}

Previous research has identified a variety of uncertainties or perceived risks in consumer decision- making, including financial, social, psychological, performance, procedural and privacy risks. This is consistent with the concept of consumers' psychic distance in CBEC. When consumers worry that they may experience mental stress (i.e. psychological risk) because they may regret their purchase decision in the future, they will postpone the purchase decision. The uncertainty of purchase procedure makes consumers postpone their purchase decision by expanding the current environment and considering more choices until the perceived risk is reduced to an acceptable and tolerable level. CBEC shopping can be regarded as an innovative shopping platform and mode independent of domestic shopping. This kind of innovation has a certain height and is not necessarily accepted by all consumers.

When consumers are accustomed to the inherent mode, they need to adjust their perception and cognitive mechanism to embrace the new shopping mode. In other words, the high uncertainty of the new shopping model is incompatible with the traditional online shopping habit. Therefore, the following hypothesis is made:

H7. The CBEC physic distance leads to online purchasing delay.

\subsection{Customer satisfaction}

As customer expectations become more specific, an overly complex consumer experience can lead to frustration and increase the likelihood of churn. It has been proven that the quality of 
ITPD

5,2

164

services (security, product quality, time and price, etc.) provided by cross-border electronic merchants greatly influences consumer satisfaction. However, the CBEC transaction itself is uncertain in the minds of consumers. If these difficulties and dangers really occur, the expectations of consumers will be greatly reduced in the future. The primary task of retailers is to attract/stimulate consumers to conduct proactive communication, so that consumers can overcome psychic distance, so as to gain trust and satisfaction (Safari et al., 2013). Therefore, we hypothesize that

H8. The greater CBEC physic distance leads to a decrease in customer satisfaction.

\section{Data collection and methods}

In recent years, $\mathrm{CBEC}$ has developed rapidly in China, so we choose Chinese consumers as research subjects. A total of 300 questionnaires were issued, and 283 were recovered, of which 249 were valid for this study. According to the survey results, the majority of CBEC users in China are in the younger generation. In addition, the questionnaires in this study also differentiate the sample survey from the time spent by consumers using CBEC. The specific situation of the respondents is shown in Table 3 . The subjects of the study used the five-point Likert-type scale to indicate the degree of consistency of each item they were asked to express (Table A1 in Appendix). The measurement items in this study are modified according to the conditions of CBEC. The questionnaire is originally in English and translated into Chinese for consumers to fill in.

In this study, there are six independent variables that affect the psychic distance of CBEC. Table 4 shows the correlation matrix of mean and standard deviation. Logistic infrastructure barriers have the highest correlation with CBEC psychic distance $(r=0.501, p s<0.01)$ and the second is related to the low level of cultural adaptation $(r=0.494$, $p s<0.01)$, followed by the payment infrastructure. Barriers $(r=0.477, p s<0.01)$, and then the foreign language difficulty $(r=0.472, p s<0.01)$. Finally, the political and legal dimension, the high level of import tariff $(r=0.460, p s<0.01)$ and the low level of government supervision $(r=0.417$, $p s<0.01)$. According to the calculated $r$ value, we can conclude that these six motivating factors are highly correlated with psychic distance $(0.417 \leq r s \leq 0.501$, $p s<0.01)$. For the results, CBEC psychic distance has the higher relevance with the online purchasing delay $(r=0.331, p s<0.01)$ and the lower correlation with the customer satisfaction $(r=-0.287, p s<0.01)$.

\begin{tabular}{llcc}
\hline Category & Classification & Frequency & Percentage \\
\hline \multirow{2}{*}{ Nationality } & China & 249 & 100 \\
Gender & Total & 249 & 100 \\
& Male & 120 & 51.9 \\
Age & Female & 129 & 48.1 \\
& Total & 249 & 100 \\
& 19 and under & 80 & 32.1 \\
& $20-29$ & 105 & 42.2 \\
Usage time of CBEC platform & $30-39$ & 53 & 22.3 \\
& 40 and over & 11 & 4.4 \\
& Total & 249 & 100 \\
& Less than 1 year & 58 & 23.3 \\
& $1-3$ years & 115 & 46.2 \\
& $3-5$ years & 67 & 26.9 \\
& More than 5 years & 9 & 3.6 \\
& Total & 249 & 100.0 \\
\hline
\end{tabular}

Table 3.

Sample characteristic 


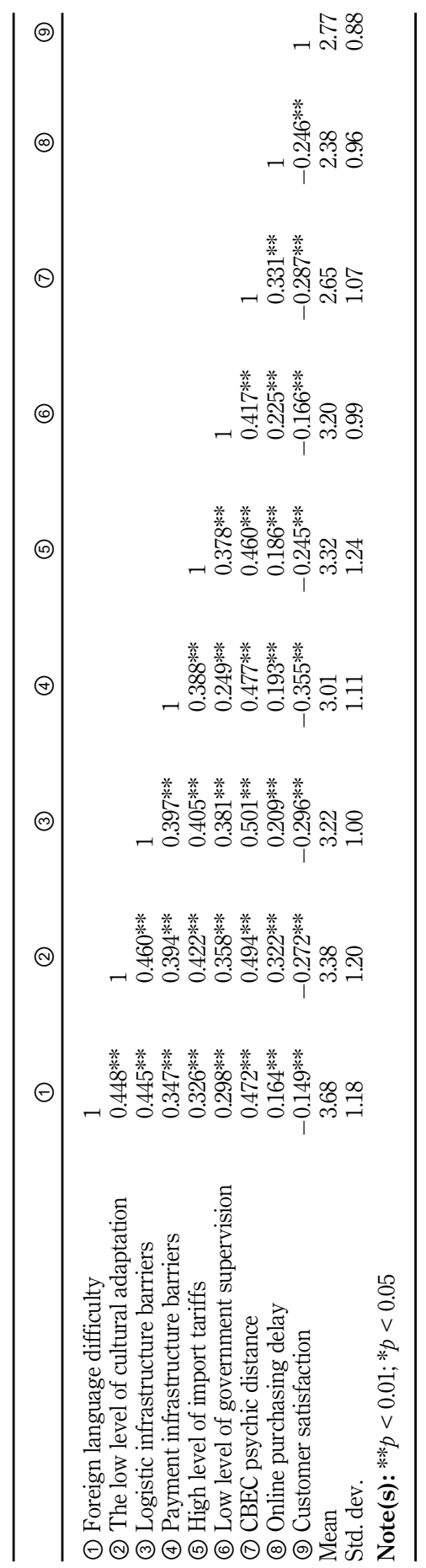

Cross-border e-commerce and consumers

165

Table 4. Correlations among constructs 
ITPD

5,2

166

In this paper, eight rationalization paths are established by using the structural equation model (SEM). The value of $\alpha$ coefficient is between 0 and 1 . The higher the $\alpha$ coefficient is, the higher the reliability is, the better the internal consistency of the questionnaire is. Generally, only when the $\alpha$ coefficient of the questionnaire is more than 0.6 , it can it be used. Cronbach's $\alpha$ values were all above 0.85 , indicating that the reliability of the questionnaire was good (Table 5).

Validity usually refers to the validity and correctness of data, that is, the degree to which data can measure the characteristics it wants to measure. The higher the validity value is, the more consistent the measured results are with the actual investigation content. AVE (average variance extracted) measures the convergence validity. AVE reflects how much of the variance explained by each latent variable comes from all topics in the latent variable. When the AVE value is greater than 0.50 , it indicates that the latent variable has good convergence validity. Composite reliability $(\mathrm{CR})$ reflects whether all topics in each latent variable consistently explain the latent variable. When the value is higher than 0.70 , it indicates that the latent variable has good construction reliability. In Table 6 , all the above items meet the above standards.

In this study, the structural equation established by AMOS was used to test the model. Fitting the model indicates that the Chi squared to degrees of freedom $\left(\chi^{2} / \mathrm{df}\right)$ value is less than 3 , NFI, CFI, IFI value $\geq 90$, GFI, AGFI value $\geq 80$, RMSEA value $\leq 08$ degree of freedom. The ratio of $c^{2}$ degrees of freedom is 1.468 , which is less than the recommended $3: 1$. The values of some fitting indices are slightly lower than the standard values, but most of them meet the research benchmark. The assumption model and path coefficients are shown in Figure 4 . The $R^{2}$ value of CBEC psychic distance 2 is $57 \%$, and online purchasing delay and customer satisfaction are 12 and $11 \%$ respectively.

The results show that $\mathrm{H} 1$ to $\mathrm{H} 8$ are all supported (Table 7). Payment infrastructure barriers $\left(\beta=0.194^{* * *}, p<0.001\right)$ are often the focus of customers' attention. Failure or difficulty in payment can lead to perceived danger in consumers' psychology, thus creating distance. At the same time, logistical infrastructure barriers $\left(\beta=0.224^{* * *}, p<0.001\right)$, such as long delivery time and inconvenience of transportation, increase customers uneasiness. Regarding the sociocultural dimension, foreign language difficulty and low level of cultural adaptation also have the significantly positive effect on the CBEC psychic distance $(\beta=0.166, \beta=0.169$, respectively, with $p s<0.05)$. When CBEC consumers enter the foreign ecommerce platform for shopping, the difficulty of foreign language will make consumers flinch. Compared with the cultural and economic dimensions, the political and legal dimension has a weaker influence on the psychic distance of $\operatorname{CBEC}\left(\beta=0.0 .132^{*}, \beta=0.136^{*}\right.$, respectively, $p s<0.05)$. On the one hand, consumers worry that import tariffs directly affect the price of goods they buy. On the other hand, due to lax government supervision, consumers will be afraid of the impact of price and product quality fraud. For the customer psychic distance caused by the results, first, CBEC psychic distance has a positive impact on consumers' purchase delay $\left(\beta=0.342^{* * *}, p s<0.01\right)$. Second, the CBEC psychic distance has a negative impact on customers satisfaction $\left(\beta=-0.339^{* * *}, p s<0.01\right)$. Surveys have found that customers unconsciously delay or give up purchases when they perceive different degrees of danger. This kind of hesitation can be understood as the concrete manifestation result of psychic distance. Psychological and emotional fluctuations also affect customer satisfaction. In view of the above results, no matter from the perspective of third-party platforms or sellers of CBEC, priority should be given to strengthening the diversification of means of payment and the speed of customs clearance of logistics.

\section{Concluding remarks}

The study shows that social and cultural dimensions have a significant positive impact on psychic distance, which further affects consumer satisfaction and purchasing behavior. 


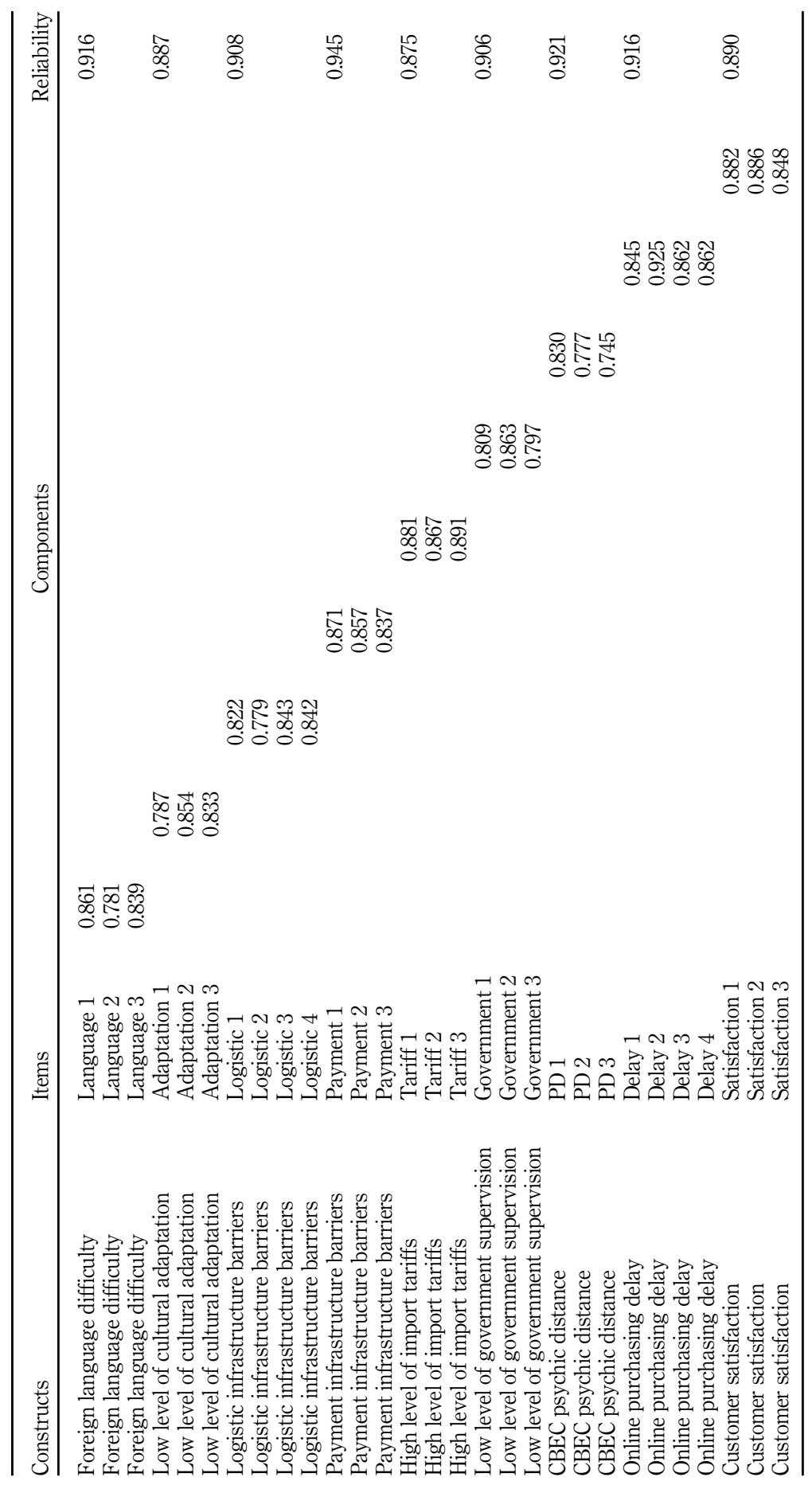

Cross-border e-commerce and consumers

167

Table 5.

Exploratory factor analysis and reliability 


\begin{tabular}{|c|c|c|c|c|c|c|c|c|}
\hline \multirow{2}{*}{$\begin{array}{l}\text { ITPD } \\
5,2\end{array}$} & \\
\hline & & Items & $\begin{array}{l}\text { Factor } \\
\text { loading }\end{array}$ & SE & $\begin{array}{c}\text { Std. } \\
\text { loading }\end{array}$ & $t$-value & $\mathrm{CR}$ & AVE \\
\hline \multirow{6}{*}{168} & \multirow{3}{*}{$\begin{array}{l}\text { Foreign language } \\
\text { difficulty }\end{array}$} & Language 1 & 0.996 & 0.066 & 0.847 & $15.033^{* * * *}$ & \multirow[t]{3}{*}{0.888} & \multirow[t]{3}{*}{0.725} \\
\hline & & Language 2 & 1.080 & 0.063 & 0.903 & $17.078^{* * * *}$ & & \\
\hline & & Language 3 & 1.000 & - & 0.809 & - & & \\
\hline & \multirow{3}{*}{$\begin{array}{l}\text { Low level of cultural } \\
\text { adaptation }\end{array}$} & Adaptation 1 & 1.029 & 0.057 & 0.867 & $18.102^{* * * *}$ & \multirow[t]{3}{*}{0.906} & \multirow{3}{*}{0.762} \\
\hline & & Adaptation 2 & 1.064 & 0.061 & 0.864 & $17.422 * * *$ & & \\
\hline & & Adaptation 3 & 1.000 & - & 0.888 & - & & \\
\hline & \multirow{4}{*}{$\begin{array}{l}\text { Logistic infrastructure } \\
\text { barriers }\end{array}$} & Logistic 1 & 1.151 & 0.070 & 0.837 & $16.396^{* * * *}$ & \multirow[t]{4}{*}{0.909} & \multirow[t]{4}{*}{0.762} \\
\hline & & Logistic 2 & 1.150 & 0.071 & 0.863 & $16.136^{* * * *}$ & & \\
\hline & & Logistic 3 & 1.000 & - & 0.876 & - & & \\
\hline & & Logistic 4 & 0.943 & 0.062 & 0.797 & $15.117^{* * * *}$ & & \\
\hline & \multirow{3}{*}{$\begin{array}{l}\text { Payment infrastructure } \\
\text { barriers }\end{array}$} & Payment 1 & 0.965 & 0.051 & 0.871 & $18.863^{* * * *}$ & \multirow[t]{3}{*}{0.918} & \multirow[t]{3}{*}{0.714} \\
\hline & & Payment 2 & 1.050 & 0.054 & 0.904 & $19.325^{* * * *}$ & & \\
\hline & & Payment 3 & 1.000 & - & 0.890 & - & & \\
\hline & \multirow[t]{3}{*}{ High level of import tariffs } & Tariff 1 & 0.951 & 0.045 & 0.895 & $21.282 * * *$ & \multirow[t]{3}{*}{0.944} & \multirow[t]{3}{*}{0.848} \\
\hline & & Tariff 2 & 1.127 & 0.042 & 0.982 & 26.612 *** & & \\
\hline & & Tariff 3 & 1.000 & - & 0.884 & - & & \\
\hline & \multirow[t]{3}{*}{$\begin{array}{l}\text { Low level of government } \\
\text { supervision }\end{array}$} & $\begin{array}{l}\text { Government } \\
1\end{array}$ & 1.210 & 0.104 & 0.741 & $11.679 * * * *$ & \multirow[t]{3}{*}{0.843} & \multirow[t]{3}{*}{0.643} \\
\hline & & $\begin{array}{l}\text { Government } \\
2\end{array}$ & 1.259 & 0.104 & 0.865 & $12.146^{* * * *}$ & & \\
\hline & & Government & 1.259 & - & 0.794 & - & & \\
\hline & \multirow[t]{3}{*}{ CBEC psychic distance } & PD 1 & 1.000 & - & 0.853 & - & \multirow[t]{3}{*}{0.922} & \multirow[t]{3}{*}{0.797} \\
\hline & & PD 2 & 0.983 & 0.047 & 0.907 & $20.773 * * *$ & & \\
\hline & & PD 3 & 0.916 & 0.047 & 0.855 & $19.334 * * *$ & & \\
\hline & \multirow[t]{4}{*}{ Online purchasing delay } & Delay 1 & 1.000 & - & 0.855 & - & \multirow[t]{4}{*}{0.918} & \multirow[t]{4}{*}{0.737} \\
\hline & & Delay 2 & 1.038 & 0.059 & 0.915 & $17.726^{* * * *}$ & & \\
\hline & & Delay 3 & 0.918 & 0.055 & 0.879 & $16.645^{* * * *}$ & & \\
\hline & & Delay 4 & 1.047 & 0.067 & 0.846 & 15.670 **** & & \\
\hline \multirow{4}{*}{$\begin{array}{l}\text { Table } 6 \text {. } \\
\text { Confirmatory factor } \\
\text { analysis results }\end{array}$} & Customer satisfaction & Satisfaction 1 & 1.000 & - & 0.824 & - & \multirow[t]{4}{*}{0.892} & 0.735 \\
\hline & & Satisfaction 2 & 1.190 & 0.071 & 0.946 & $16.802^{* * * *}$ & & \\
\hline & & Satisfaction 3 & 1.044 & 0.072 & 0.795 & $14.523 * * *$ & & \\
\hline & $\operatorname{Note}(\mathbf{s}): * * * p<0.01, * * p$ & $=0.05$ & & & & & & \\
\hline
\end{tabular}

When opening a cross-border e-commerce shopping website, language barriers will make users unable to understand specific product information and payment steps, which leads to psychological anxiety. Direct translation of language may also lead to misunderstandings among consumers, and contextualization of language is also the focus of attention of website managers. Many people believe that with the continuous development of free trade and globalization, the consumption habits and cognition of global consumers are gradually unifying. Cultural heterogeneity is the key factor in understanding consumer behavior differences. Website managers should reflect the commonality of multi-ethnic integration in advertising and represent the unique cultural details of different cultures, thus triggering the resonance of consumers and stimulating the purchasing intention.

Our analysis suggests that the most influential economic dimension is as follows: High logistical cost and long distribution cycles resulting from the expansion of domestic markets to foreign markets impact the barriers that customers face when engaging in e-commerce. Logistic for after-sales service are difficult to standardize and are one of the issues that network managers need to consider. Multi-country logistics and multi-mode logistics need to play a more comprehensive synergistic role in optimizing distribution routes, clustering and sorting of goods, and rationally allocating logistics tools. The localization of payment modes 

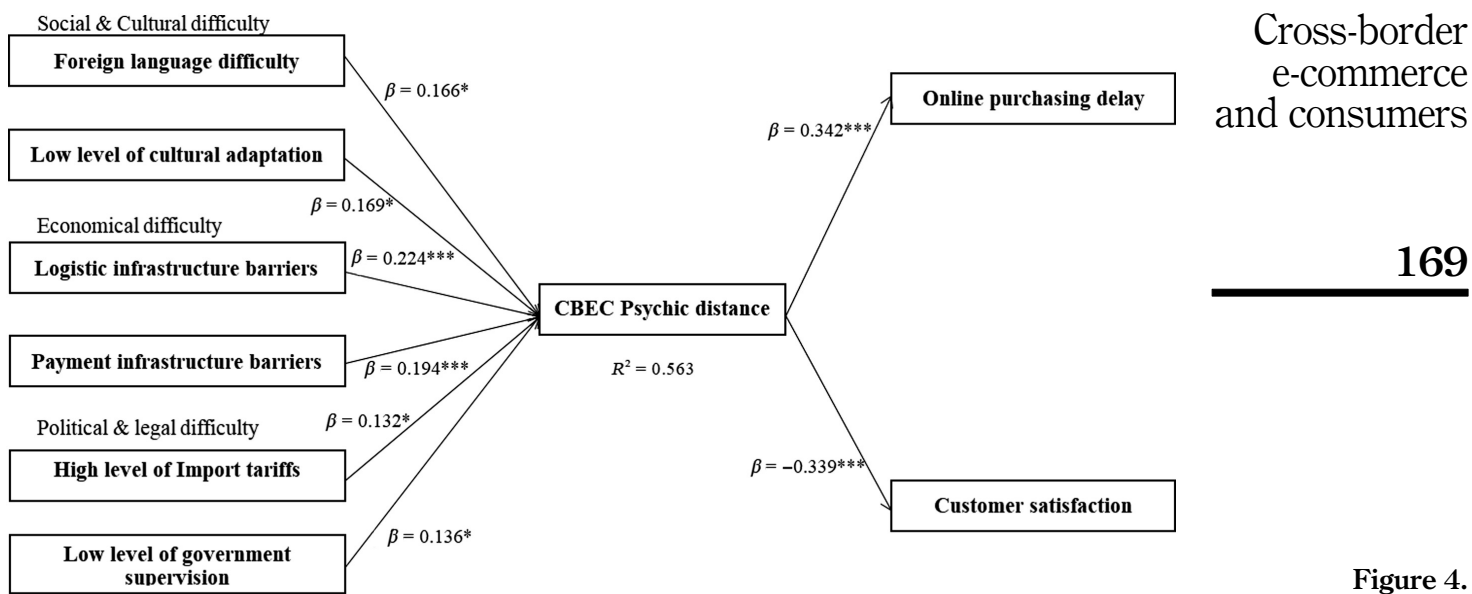

Note(s): $X^{2}=521.945, \mathrm{df}=354, \mathrm{GFI}=0.88, \mathrm{AGFI}=0.87, \mathrm{NFI}=0.913, \mathrm{CFI}=0.97, \mathrm{IFI}=0.966$, RMSEA $=0.044 ; * * * p<0.01, * * p<0.05$

\begin{tabular}{llcc}
\hline & Path & Coefficient & Results \\
\hline H1 & Foreign language difficulty $\rightarrow$ CBEC psychic distance & $0.166^{*}$ & Supported \\
H2 & Low level of cultural adaptation $\rightarrow$ CBEC psychic distance & $0.169^{*}$ & Supported \\
H3 & Logistic infrastructure barriers $\rightarrow$ CBEC psychic distance & $0.224^{* * *}$ & Supported \\
H4 & Payment infrastructure barriers $\rightarrow$ CBEC psychic distance & $0.194^{* * *}$ & Supported \\
H5 & High level of import tariffs $\rightarrow$ CBEC psychic distance & $0.132^{*}$ & Supported \\
H6 & Low level of government supervision $\rightarrow$ CBEC psychic distance & $0.136^{*}$ & Supported \\
H7 & CBEC psychic distance $\rightarrow$ Online purchasing delay & $0.342^{* * *}$ & Supported \\
H8 & CBEC psychic distance $\rightarrow$ Customer satisfaction & $-0.339^{* * *}$ & Supported
\end{tabular}

Figure 4.

The result of research model

Note(s): $* * * p<0.01 ; * * p<0.05$

Table 7.

Path analysis

will promote further breakthroughs in CBEC. In considering the potential risks, such as credit risk and network risk, in online payment of $\mathrm{CBEC}$, website managers should speed up the construction of a secure and credible third-party payment system and improve the cooperation supervision mechanism of cross-border payment.

In this analysis, although the psychic distance between political and legal dimensions is considered to be very small, it also indirectly indicates that consumers' cognition and understanding of legal and political aspects is weak. Due to the complexity of customs tariff, cross-border rights protection and other issues involved in $\mathrm{CBEC}$, it is more necessary for relevant departments to strengthen the legal publicity to consumers from the perspective of consumers' interests and constantly improve the legal remedy measures and approaches.

Although this study has some insight that can help promoting the development of CBEC, there are still some limitations. First, sample selection may affect the research results. The cultural environment of different countries and the speed of Internet development may have an impact on the results. Second, this study only investigated the impacts of external factors on consumer's psychic distance; however, it did not make assumptions about the impact of internal factors to influence them. In addition to the above demographic variables, the difference of local education level and the imbalance of income level will also lead to the deviation of psychic distance in cross-border shopping. For the follow-up of this article, the 
ITPD

5,2

internal factors of cross-border consumers are still the direction of investigation. In this paper, the research on the psychic distance of CBEC consumers is on the horizontal level, without subdividing the psychic distance, because the level of psychic distance of different consumers can be high or low. Similarly, in terms of independent variables, the different degree of adaptation sensitivity of cross-border consumers to culture is also the direction of subsequent research.

\section{References}

Adeleke, A. and Suraju, A.A. (2012), "The determinants of customer loyalty in Nigeria's GSM market", International Journal of Business and Social Science, Vol. 3 No. 14, pp. 209-222.

Boeuf, B. and Senecal, S. (2014), "Online international outshopping experience: proposition of a research model", Research at Applications on Marketing, Vol. 28 No. 3, pp. 110-119.

Chen, S., He, Q. and Xiao, H. (2020), "A study on cross-border e-commerce partner selection in B2B mode", Electronic Commerce Research, pp. 1-21, doi: 10.1007/s10660-020-09403-6.

Cho, C.-H., Kang, J. and Cheon, H.J. (2006), "Online shopping hesitation”, Cyber Psychology and Behavior, Vol. 9 No. 3, pp. 261-274.

Ding, F., Huo, J. and Campos, J. (2017), "The development of cross border e-commerce", Business and Management Research, AEBMR, Vol. 37, pp. 370-383.

Dow, D. and Karunaratna, A. (2006), "Developing a multidimensional instrument to measure psychic distance stimuli”, Journal of International Business Studies, Vol. 37 No. 5, pp. 578-602.

Eun-Jin, L. (2014), "The effects of internet fashion consumer's anticipated regret and selection difficulty on decision making delay and purchase switching intention", Journal of the Korean Society of Clothing and Textiles, Vol. 37 No. 4, pp. 526-539.

European Commission (2016a), Commission Presents Roadmap for Completing the Single Market for Parcel Delivery, Press Release, Brussels.

European Commission (2016b), Proposal for a Regulation of the European Parliament and of the Council on Cross-Border Parcel Delivery Services, Press Release, Brussels.

Evans, J. and Mavondo, F.T. (2002), "Psychic distance and organizational performance: an empirical examination of international retailing operations", Journal of International Business Studies, Vol. 33 No. 3, pp. 515-532.

Ferdous, A.S. and Towfique, B. (2008), "Consumer sentiment towards marketing in Bangladesh: the relationship between attitudes to marketing, satisfaction and regulation”, Marketing Intelligence and Planning, Vol. 26 No. 5, pp. 481-495.

Ganesh, J., Reynolds, K.E., Luckett, M. and Pomirleanu, N. (2010), "Online shopper motivations, and estore attributes: an examination of online patronage behaviour and shopper typologies", Journal of Retailing, Vol. 86 No. 1, pp. 106-115.

Gibbs, J., Kraemer, K.L. and Dedrick, J. (2003), "Environment and policy factors shaping global ecommerce diffusion: a cross-country comparison", Information Society, Vol. 19 No. 1, pp. 5-18.

Håkanson, L. and Ambos, B. (2010), "The antecedents of psychic distance", Journal of International Management, Vol. 16 No. 3, pp. 195-210.

Håkanson, L. and Dow, D. (2012), "Markets and networks in international trade: on the role of distances in globalization", Management International Review, Vol. 52 No. 6, pp. 761-789.

Hong-Youl, Ha. and Helen, P. (2005), "Effects of consumer perceptions of brand experience on the web: brand familiarity, satisfaction and brand trust", Journal of Consumer Behaviour, Vol. 4 No. 6, pp. $438-452$.

Johanson, J. and Wiedersheim-Paul, F. (1975), "The internationalization of the firm? Four Swedish cases", Journal of Management Studies, Vol. 12 No. 3, pp. 305-323.

Kawa, A. (2014), "Logistyka w obsłudze handlu elektronicznego", Logistics in Service for E-Commerce, Logistyka, Vol. 5, pp. 36-38. 
Kowalski, P. (2005), "Impact of changes in tariffs on developing countries' government revenue", OECD Trade Policy Papers, No. 18.

Kuo, C.L. and Fang, W.C. (2008), "Psychic distance and FDI location choice: empirical examination of Taiwanese firms in China Department of Business Administration", Asia Pacific Management Review, Vol. 14 No. 1, pp. 85-106.

Lawrence, J.E. and Tar, U.A. (2010), "Barriers to ecommerce in developing countries", Information. Society and Justice, Vol. 3 No. 1, pp. 23-35.

Lim, K.H., Leung, K., Sia, C.L. and Lee, M.K.O. (2004), "Is ecommerce boundary-less? Effects of International Business Studies, Vol. 35 No. 6, pp. 545-559.

Luna, D., Peracchio, L.A. and Juan, M.A.D. (2002), "Cross-cultural and cognitive aspects of web site navigation", Journal of the Academy of Marketing Science, Vol. 30 No. 4, pp. 397-410.

Mann, M.K. (2012), "The role of need for distinctiveness and acculturation in young, urban Indian consumers' purchase intention for western brands at western retail formats: an application of theory of planned behaviour", PhD dissertation, Auburn University, August 4, 2012.

Marcos-Llina, M. and Juan Garau, M. (2009), "Effects of language anxiety on three proficiency-level courses of spanish as a foreign language”, Foreign Language Annals, Vol. 42 No. 1, pp. 94-111.

Okholm, H.B., Thelle, M.H., Möller, A., Basalisco, B. and Rølmer, S. (2013), "E-commerce and delivery: a study of the state of play of EU parcel markets with particular emphasis on e-commerce", Copenhagen Economics, available at: https://dwz.cn/XwmvBeAZ (accessed 15 June 2014).

Peltokorpi, V. and Vaara, E. (2014), "Knowledge transfer in multinational corporations: productive and counterproductive effects of language- sensitive recruitment", Journal of International Business Studies, Vol. 45 No. 5, pp. 600-622.

Prime, N., Obadia, C. and Vida, I. (2009), "Psychic distance in exporter-importer relationships: a grounded theory approach", International Business Review, Vol. 18 No. 2, pp. 184-198.

Safari, A., Thilenius, P. and Hadjikhani, A. (2013), “The impact of psychic distance on consumers' behavior in international online purchasing", Journal of International Consumer Marketing, Vol. 25 No. 4, pp. 234-249.

Schaffer, E. (2000), “A better way for web design”, Information Week, Vol. 784, p. 194.

Shenkar, O. (2001), "Cultural distance revisited: towards a more rigorous conceptualization and measurement of cultural differences", Journal of International Business Studies, Vol. 32 No. 3, pp. 519-535.

Sinkovics, R.R., Yamin, M. and Hossinger, M. (2007), "Cultural adaptation in cross border e-commerce: a study of German companies", Journal of Electronic Commerce Research, Vol. 8 No. 4, pp. 221-235.

Skarmeas, D., Katsikeas, C.S., Spyropoulou, S. and Sangari, E.S. (2008), "Market and supplier characteristics driving distributor relationship quality in international marketing channels of industrial products”, Industrial Marketing Management, Vol. 37 No. 1, pp. 23-36.

Sousa, C. and Bradley, F. (2006), "Cultural distance and psychic distance: two peas in a pod?", Journal of International Marketing, Vol. 14 No. 1, pp. 49-70.

Xue, W., Li, D. and Pei, Y. (2016), “The development and current of cross-border e-commerce”, Whiceb 2016 Proceedings, Vol. 53, pp. 131-138.

Yamin, M. and Sinkovics, R.R. (2006), "Online internationalisation, psychic distance reduction and the virtuality traps”, International Business Review, Vol. 15 No. 4, pp. 339-360.

Yu, D., Dong, D.H., Liu, R.M. and Yuan, Y.D. (2007), "Research on the sources, types and influencing factors of online shopping risks", Journal of Dalian University of Technology (Social Sciences), Vol. 2007, pp. 17-23.

Yu, Y. and Dean, A. (2001), "The contribution of emotional satisfaction to consumer loyalty", International Journal of Service Industry Management, Vol. 12 No. 3, pp. 234-251. 
Appendix

5,2

\begin{tabular}{|c|c|c|c|}
\hline Constructs & Mea & surement items & Researchers \\
\hline Psychic distance & $\begin{array}{l}(1) \\
(2) \\
(3)\end{array}$ & $\begin{array}{l}\text { When I use a cross-border e-commerce platform, I } \\
\text { will perceive the cultural distance } \\
\text { When I use a CBEC platform, I will perceive the } \\
\text { economical distance } \\
\text { When I use a CBEC platform, I will perceive the legal } \\
\text { and political distance }\end{array}$ & $\begin{array}{l}\text { Dionysis Skarmeas } \\
\text { et al. (2008) }\end{array}$ \\
\hline $\begin{array}{l}\text { Foreign language } \\
\text { difficulty }\end{array}$ & $\begin{array}{l}(2) \\
(3)\end{array}$ & $\begin{array}{l}\text { When I choose CBEC platform, it is the difficulty of } \\
\text { language communication affecting my choice of this } \\
\text { platform } \\
\text { I will prefer to choose a CBEC platform in my mother } \\
\text { tongue to purchase goods } \\
\text { Difficulties in foreign languages can affect my access } \\
\text { to information about products }\end{array}$ & $\begin{array}{l}\text { Marcos-Llina and } \\
\text { Juan Garau (2009) }\end{array}$ \\
\hline $\begin{array}{l}\text { Low level of cultural } \\
\text { adaptation }\end{array}$ & $\begin{array}{l}(1) \\
(2) \\
(3)\end{array}$ & $\begin{array}{l}\text { Social values in different countries will affect my } \\
\text { cross-border shopping experience } \\
\text { I think my lifestyle is almost different from that of } \\
\text { my peers in different countries } \\
\text { When I use CBEC platform, I am not used to } \\
\text { browsing different cultural content }\end{array}$ & $\begin{array}{l}\text { Manveer Kaur Mann } \\
\text { (2012) }\end{array}$ \\
\hline $\begin{array}{l}\text { Logistic infrastructure } \\
\text { barriers }\end{array}$ & $\begin{array}{l}(1) \\
(2) \\
(3) \\
(4)\end{array}$ & $\begin{array}{l}\text { I am afraid that goods purchased overseas will have } \\
\text { a long transportation time } \\
\text { I am afraid that goods purchased directly from } \\
\text { overseas will not be delivered on time } \\
\text { If goods purchased directly overseas are lost in the } \\
\text { distribution process, I will feel uneasy } \\
\text { I feel uneasy when I buy goods that are not what I } \\
\text { need through direct overseas purchases }\end{array}$ & Yu et al. (2007) \\
\hline $\begin{array}{l}\text { Payment infrastructure } \\
\text { barriers }\end{array}$ & $\begin{array}{l}\text { (1) } \\
(2) \\
(3)\end{array}$ & $\begin{array}{l}\text { I will feel uneasy about the failure of online payment, } \\
\text { which may lead to loss of money } \\
\text { I'm uncomfortable with unfamiliar payment } \\
\text { methods } \\
\text { When I use the payment system, I worry about the } \\
\text { leak of private information }\end{array}$ & Yu et al. (2007) \\
\hline $\begin{array}{l}\text { High level of import } \\
\text { tariffs }\end{array}$ & $\begin{array}{l}\text { (1) } \\
(2) \\
(3)\end{array}$ & $\begin{array}{l}\text { Tariff adjustment will affect my use of CBEC } \\
\text { platform } \\
\text { High tariffs and product prices will make me switch } \\
\text { to other e-commerce platforms } \\
\text { I have no intention of paying higher prices or tariffs } \\
\text { online }\end{array}$ & $\begin{array}{l}\text { Adeleke and Suraju } \\
(2012)\end{array}$ \\
\hline $\begin{array}{l}\text { Low level of } \\
\text { government } \\
\text { supervision }\end{array}$ & $\begin{array}{l}(1) \\
(2)\end{array}$ & $\begin{array}{l}\text { I feel uneasy if the government did not set minimum } \\
\text { quality standards for all products sold to consumers } \\
\text { The government should exercise more regulatory } \\
\text { power over the advertising and marketing activities } \\
\text { of internet dealers } \\
\text { The government should test the actual quality of the } \\
\text { products of online distributors and inform } \\
\text { consumers }\end{array}$ & $\begin{array}{l}\text { Ferdous and } \\
\text { Towfique (2008) }\end{array}$ \\
\hline
\end{tabular}

Table A1. 


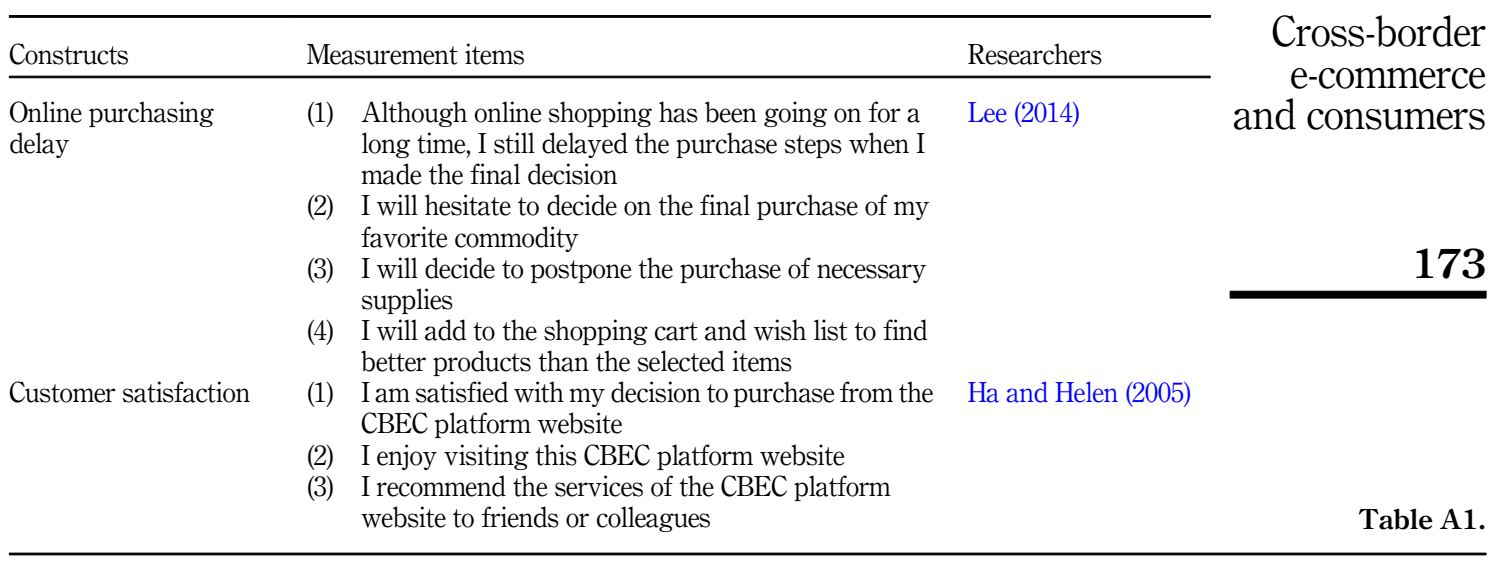

\section{Corresponding author}

Hag-Min Kim can be contacted at: edoctor@khu.ac.kr

For instructions on how to order reprints of this article, please visit our website: 